American Journal of Environmental Sciences 4 (2): 129-135, 2008

ISSN 1553-345X

(C) 2008 Science Publications

\title{
Appraisal of Thermal Properties of Mud in the Ariake Sea, Japan
}

\author{
M. Azizul Moqsud, Shigenori Hayashi, Yan Jun Du, Daisuke Suetsugu \\ Institute of Lowland Technology, Saga University, 1 Honjo, Saga 840-8502, Japan
}

\begin{abstract}
In order to explore the thermal properties of the Ariake Sea mud and to find out the affecting factors which affect these values, a portable thermal properties analyzer was used. Thermal conductivity, thermal resistivity, thermal diffusivity and volumetric heat capacity of the mud samples collected from both the tidal flat and inside the deep sea were measured in the laboratory. The thermal properties of mud collected from tidal flat showed a different trend from the mud collected from inside the sea due to the enough exposure to the sunlight and vigorous exchange of sea water in the tidal flat. Thermal conductivity of the Ariake mud was reduced $85-90 \%$ after it was oven dried and was increased up to $30 \%$ after the ignition loss test. Thermal resistivity of the Ariake mud increased dramatically after oven dried and it was less affected by the organic matter content. Thermal diffusivity was decreased $10-30 \%$ after oven dry however it increased up to $40 \%$ after the ignition loss test. The volumetric heat capacity of the Ariake mud was reduced up to $90 \%$ and increased $40 \%$ after the oven dry and ignition loss, respectively.
\end{abstract}

Keywords: Thermal conductivity, thermal resistivity, thermal diffusivity, tidal mud, volumetric heat capacity

\section{INTRODUCTION}

The Ariake Sea is one of the best-known semiclosed shallow seas in Japan. The vast tidal flat of the Ariake Sea, which is almost $40 \%$ of the total tidal flat area of Japan, is famous for its rich fishery products and Porphyra sp. (sea laver) cultivation. However, a dramatic decrease of catch of shells, such as Sinonovacula constricta, Atrina pectinata and Crassostrea gigas is observed both in the tidal flat and inside the deep sea mud in the Ariake Sea for the last 3 decades. According to Saga agricultural and forestry statistical society (SAFSS), Japan 2006, Crassostrea gigas, usually living near the surface mud, dropped from $7.99 \times 10^{5} \mathrm{~kg}$ in 1979 to only $1.26 \times 10^{5}$ $\mathrm{kg}$ in 1999; that of Atrina pectinata, living in the upper $0.10-0.15 \mathrm{~m}$ of the mud, declined from $1.34 \mathrm{x}$ $10^{7} \mathrm{~kg}$ in 1976 to $7.9 \times 10^{4} \mathrm{~kg}$ in 1999 and the situation in the case of Sinonovacula constricta, living in the depth of 0-0.70 m of the mud, was even worse: $1.7 \mathrm{x}$ $10^{5} \mathrm{~kg}$ catch in 1976 dropped to practically nil by 1992 . The cause for the declination of the fishery products is the unfavorable geo-environmental condition of the Ariake Sea created by acid treatment practice for the Porphyra sp. (sea weed) cultivation ${ }^{[10,}{ }^{13}$. The Porphyra sp. is a favorite food for the people of Japan and Korea and it is the main earning source of the huge population near the Ariake Sea area. During the period of the cultivation (December-March), the medicine $(\mathrm{pH}=2)$ is used as the disinfectant acid to treat the Porphyra sp. cultivated in the sea. This organic acid provides ample of foods for the sulphate reducing bacteria living in the mud and consequently increase the sulphide content in the mud. The generation of sulphide is also influenced by the seasonal temperature and shows a higher value during the summer and the late autumn as bacteria becomes more active in the higher temperature ${ }^{[11]}$. The higher sulphide content created by acid treatment practice is the main reason for the unfavorable geoenvironmental condition for the benthos in the Ariake Sea. Moreover, the activities of the benthos depend strongly on the thermal environment near the sediment surface. Photosynthetic capacity of micro phytobenthos on an intertidal flat was strongly influenced by mud surface temperature ${ }^{[4]}$. The filtration rate of bivalves was dependent on the water temperature (Hosokawa et al., 1996). As a result, to evaluate geo-thermal environment is important especially for the acid contaminated Ariake Sea. Thermal properties dictate the storage and movement of heat in soils and as such influence the temperature and heat flux in soils as a function of time and depth ${ }^{[1]}$.

Corresponding Author: $\quad$ M. Azizul Moqsud, Institute of lowland Technology, Saga University,1 Honjo Saga 8408502 Tel: 81-952-244822 Fax: 81-952-288189 E-mail: moqsudsaga@yahoo.com 


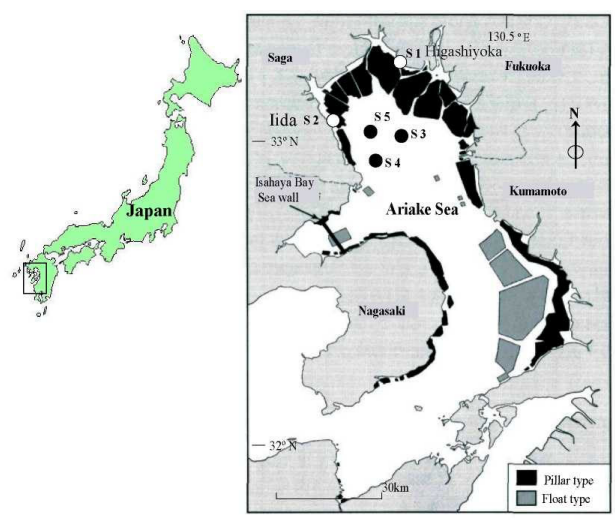

Fig. 1: Map of the Ariake Sea indicating the sampling sites and different types of Porphyra sp. cultivation areas

In recent years, considerable efforts have gone into developing techniques to determine these properties ${ }^{[19]}$. The propagation of heat in a soil is governed by its thermal characteristics ${ }^{[6]}$. Main factors influencing soil thermal properties are mineralogical composition, the organic content and water content ${ }^{[5}$, ${ }^{21]}$. As a matter of fact, no study had been carried out before to get the information about the thermal properties of the Ariake sea mud. The objective of the study is to evaluate the thermal properties of the Ariake Sea mud collected from both tidal flat and inside the deep sea and to observe the influence of water content and organic content on the thermal properties of the Ariake Sea mud.

Study Areas: Two sampling sites from tidal flat areas sample 1(S1) and sample 2 (S2) and three sampling sites (sample 3 (S3), sample 4 (S4) and sample 5 (S5)) inside the Ariake Sea were selected as the study areas. Figure 1 shows the locations of the two tidal flat areas (Higashiyoka and Iida) and the three different areas inside the sea, along with the two types (pillar type and float type) of Porphyra sp. cultivation areas. The tidal currents sweep into the sea and move northwards along the eastern shoreline and create a counterclockwise water movement. This would sweep the finer suspended particles delivered by rivers on the east side towards the inland end, where sedimentation would occur ${ }^{[18]}$. Sediments in the Ariake Sea tidal flats are medium sand to silty mud. Medium sand, which accounts for $71 \%$ of the total tidal flats, is located mainly in the east and south coast areas ${ }^{[2]}$. The silty mud is mainly in the bay head. Higashiyoka tidal flat located in the bay head was chosen as a study area
(S1) which is near to Chikugo river (the biggest river in Kyushu Island), Okinohota river as well as other rivers and thought to be affected by the river waters. Another study area in tidal flat was Iida (S2), which seems to be the most affected by the acid treatment practice. The other three study areas are chosen inside the Ariake Sea where all the time they are under water. The sample 1 and sample 2 (Higashiyoka and Iida) were collected during the ebb tide and the tidal flat was exposed to the sun directly. The other three mud samples (S3, S4, and S5 in Figure 1) were collected from under the sea water in different depths in different locations in the Ariake Sea. The sample collection was done in the last week of April 2006 Ariake Sea.

\section{MATERIALS AND METHODS}

Laboratory tests were conducted to evaluate the thermal properties at the controlled room temperature at $20^{\circ} \mathrm{C}$. In-situ samples were collected by inserting vertically a thin wall steel tube sampler with a diameter of $0.07 \mathrm{~m}$ and a length of $0.90 \mathrm{~m}$ at five sites. For sample collection from tidal flat region an amphibious ship was used. The mud samples from tidal flat were collected during the ebb tide and about $40 \mathrm{~m}$ distance from the shore line. For sample collection from inside the sea, a ship was used. The ship was anchored in the predetermined location which was fixed by the global positioning system (GPS) and the average sea water depth of the samples was about $20 \mathrm{~m}$. The diver dived into the sea and collected the mud samples by inserting the steel tube sampler into the sea bed floor and capped the two openings of the tube. The sample was then sliced into $0.05 \mathrm{~m}$ layers in the laboratory to measure the thermal properties in each layer. The thermal properties analyzer KD2 Decagon Devices, Inc. was used to measure the thermal properties. Briefly, the measurement was done by inserting the needle completely into the samples. The KD2 sensor needle contains both a heating element and a thermistor. The controller module contains a battery, a 16-bit microcontroller /AD converter, and power control circuitry. When the measurement begins, the microcontroller waits for 90 seconds for temperature stability, and then applies a known amount of current for 30 seconds to a heater in the amount of power supplied to the heater. The probe's thermistor measure the changing temperature for 30 seconds while the microprocessor stores the data. At the end of the reading, the controller computes the thermal conductivity and diffusivity using the change in 
temperature and time data. Thermal resistivity is computed as the reciprocal of thermal conductivity. The data of thermal conductivity, thermal diffusivity and thermal resistivity are shown directly in the digital display of the thermal properties analyzer. The volumetric heat capacity was calculated by dividing thermal conductivity by thermal diffusivity. To observe some factors which affect the thermal properties value of the tidal mud, water content test and ignition loss test were conducted in the laboratory to determine the water content and organic content effects, respectively. Water content test was conducted by following ASTM D 2216 and ignition loss test was conducted by following the standard methods of soil analysis ${ }^{[3]}$.

\section{RESULTS AND DISCUSSION}

Thermal conductivity: Thermal conductivity of a matter is the properties of that matter which indicate the ability to transfer heat. Figure 2 illustrates that the variation of thermal conductivity at different depths in the Ariake sea mud. In the sample of tidal flats (S 1 and S 2), the variation is more than the other samples collected from deep sea. This is probably due to much turbulation of the tidal flat mud in the tidal flat area and introduces various kinds of matter during the tidal water movement as well as the direct exposure to the sun light during the low tide. The bioturbation and bioirrigation were more in the tidal flat areas than in the deep sea mud (Hosokawa et al., 1996). All the samples show great variations in near surface (0-0.20 $\mathrm{m})$ region but less variation was observed in deeper section. Thermal conductivity of mud varies with soil texture, water content and organic matter content ${ }^{[9]}$. The water content of the Ariake mud is always over $130 \%$ in different depths, which indicates that the conductivity of the Ariake Sea mud is not affected by the water content at different depths ${ }^{[15]}$. Thermal conductivity of soil is become almost constant after reaching above $120-125 \%$ of water content ${ }^{[15]}$. In Figure 2, it is seen that in sample $1 \&$ sample 2 at 0.10 $\mathrm{m}$ depth the value is the highest $\left(0.70 \mathrm{~W} / \mathrm{m}^{\circ} \mathrm{C}\right)$. This is probably due to some difference in the mineralogy or organic content from the consequent layers. Thermal conductivity becomes almost constant at $0.30 \mathrm{~m}$ depth. Figure 3 shows that thermal conductivity of the Ariake mud is reduced up to $85-90 \%$ after it was oven dried ( $0 \%$ water content).Sample 3 illustrates the peak conductivity value of $0.75 \mathrm{~W} / \mathrm{m}{ }^{\circ} \mathrm{C}$ and mud samples from Higashiyoka tidal flat shows the lowest value of $0.65 \mathrm{~W} / \mathrm{m}^{\circ} \mathrm{C}$. After oven dried, they show $0.70 \mathrm{~W} / \mathrm{m}^{0}$ $\mathrm{C}$ and $0.40 \mathrm{~W} / \mathrm{m}^{0} \mathrm{C}$, respectively. Figure 4 shows that the thermal conductivity increased after the ignition loss. The values increase $10-30 \%$ after the ignition loss test as it removes the organic matter. The effects of organic matter on thermal conductivity of the tidal flat mud or inside sea mud were not much measured before in the world. So we were unable to compare our results with others from previous studies.

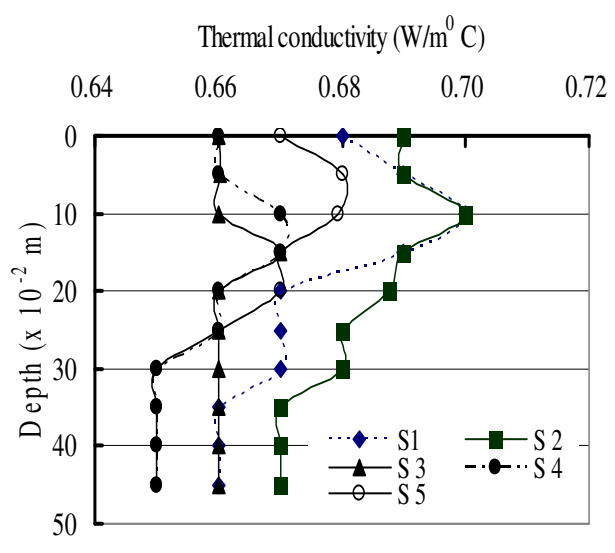

Fig. 2: Variation of thermal conductivity of the samples in different depths

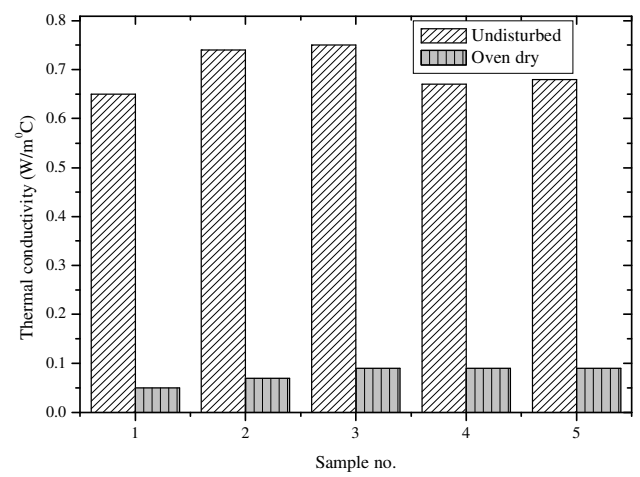

Fig. 3: Variation of thermal conductivity of the samples after oven dry

Thermal resistivity: Thermal resistivity is the property of a matter which hinders heat to transfer from surface to the deeper part. The thermal resistivity is an important part for the thermal environment of the tidal flat as well as for the deep sea mud ${ }^{[16]}$.Figure 5 demonstrates that the variation of thermal resistivity with depth of the samples of the tidal flat and deep sea mud. The thermal resistivity is varied much in the subsurface $(0-0.2 \mathrm{~m})$ area and it showed a relative stable value in the deeper area. Iida tidal flat mud shows the 


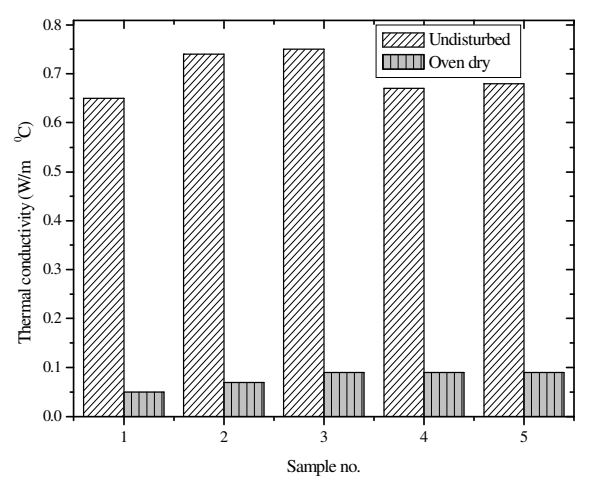

Fig. 4: Variation of thermal conductivity of the samples after ignition loss

\section{Themal resistivity $\left(\mathrm{m}^{0} \mathrm{CW}\right)$}

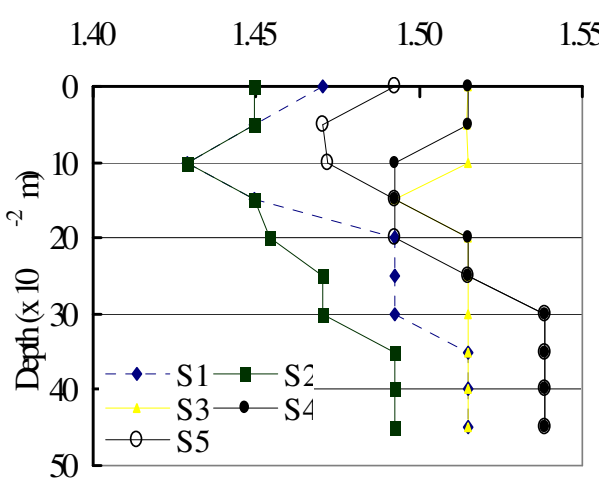

Fig. 5: Variation of thermal resistivity of the samples after oven dry

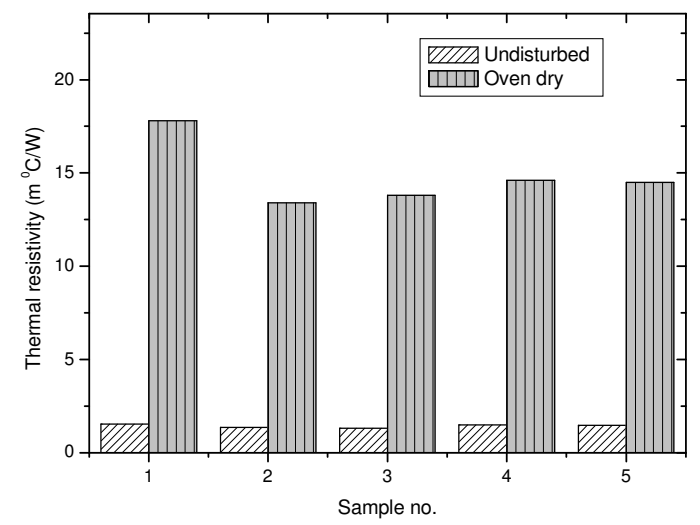

Fig. 6: Variation of thermal resistivity of the samples after oven dry

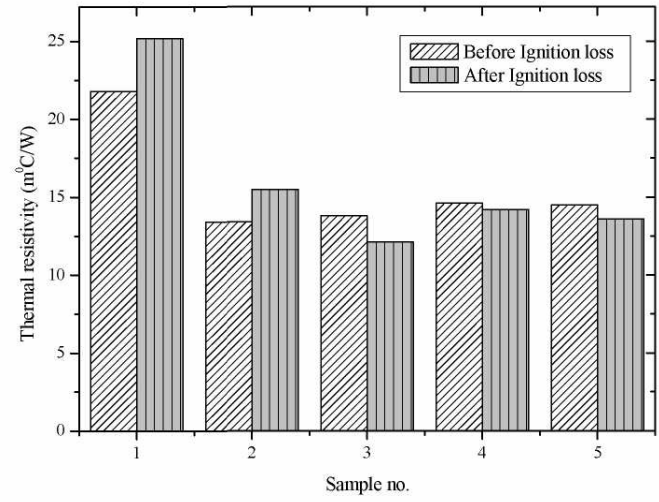

Fig. 7: Variation of thermal resistivity of the samples after ignition loss

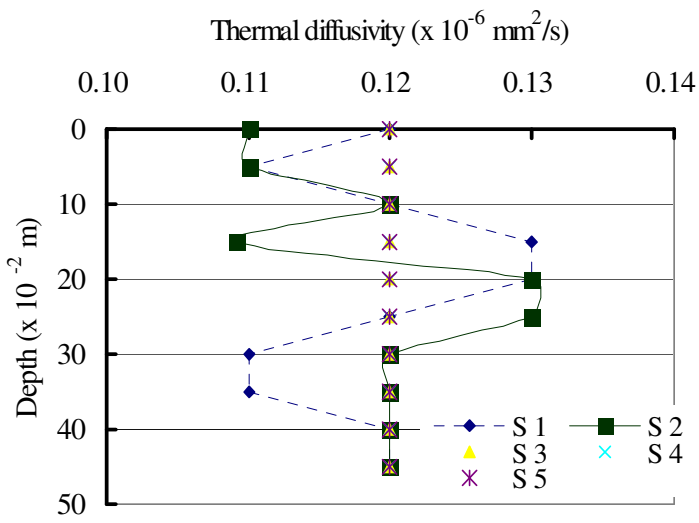

Fig. 8: Variation of thermal diffusivity of the samples at different depths

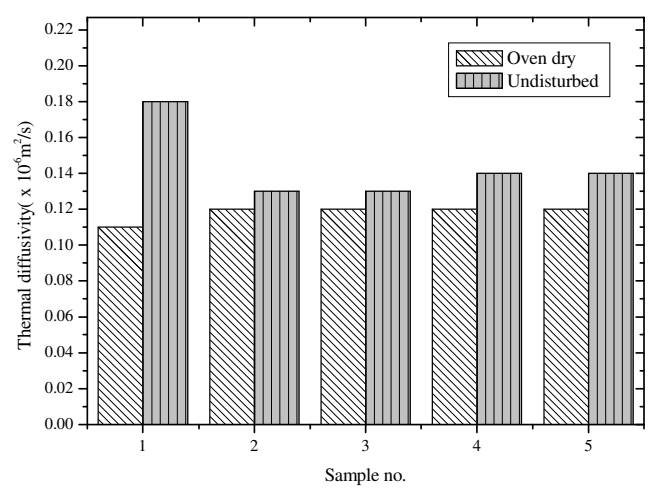

Fig. 9: Variation of thermal diffusivity of the samples after oven dry 


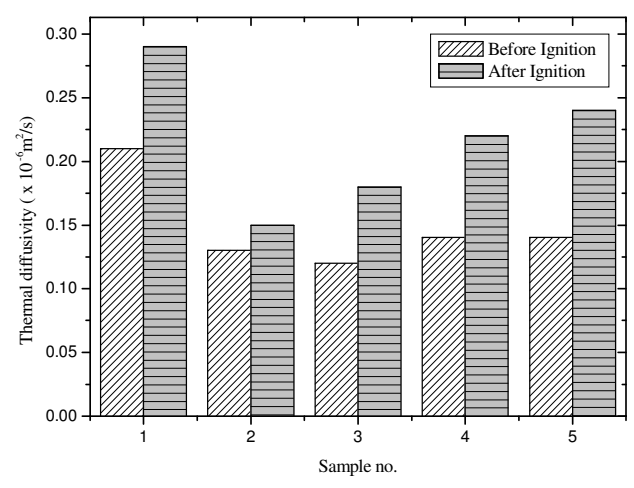

Fig. 10: Variation of thermal diffusivity of the samples after ignition loss

$$
\text { Volumetric heat capacity }\left(\mathrm{M} / \mathrm{m}^{30} \mathrm{C}\right)
$$

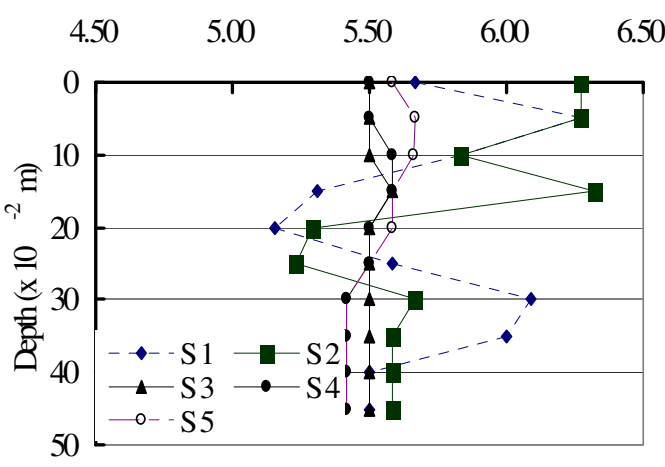

Fig. 11: Variation of volumetric heat capacity of the samples at different depths

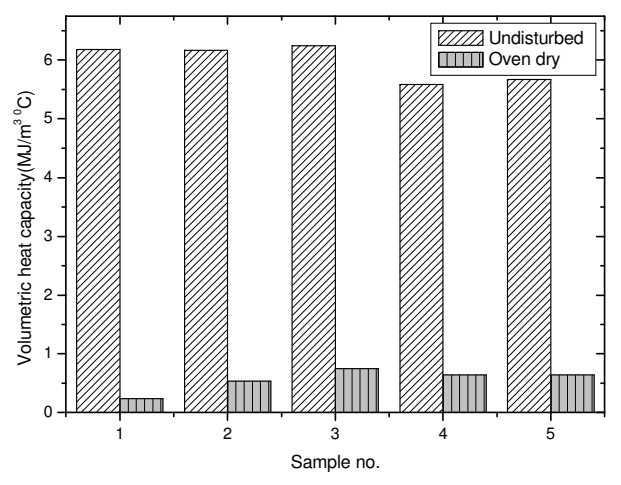

Fig. 12: Variation of volumetric heat capacity of the samples after oven dry

lowest peak (less than $1.45 \mathrm{~m}{ }^{\circ} \mathrm{C} / \mathrm{W}$ ) value in $0.10 \mathrm{~m}$ depth. Except sample 3, the mud-samples collected from inside the sea show a relatively small variation in the thermal resistivity. For sample 2, at $0.10 \mathrm{~m}$ depth, thermal resistivity shows the minimum value and this is due to the same reason as it showed the highest value of thermal conductivity in that layer (Figure 2).

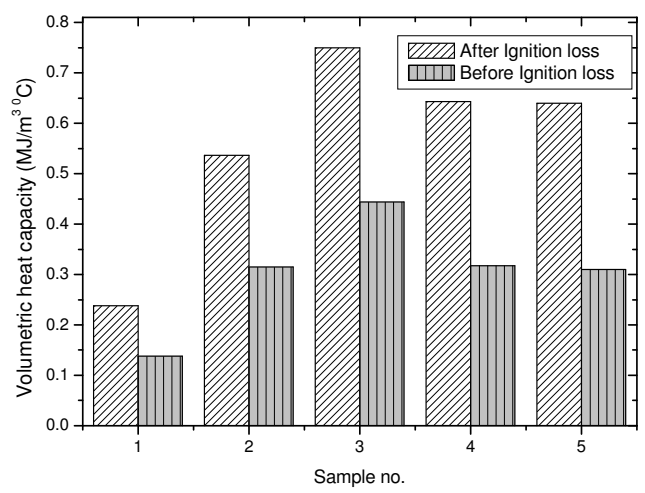

Fig. 13: Variation of volumetric heat capacity of the samples after ignition loss

However, after oven dry, the mud samples show a dramatic increase of the thermal resistivity. The water content in the mud increases the thermal conductivity and consequently decreases the thermal resistivity. The dry mud particles have less contact area for heat transfer as well as air has 20 times more thermal resistivity than water which influences the value. The soil skeleton acts as an insulator when they were dry. For this reason, the thermal resistivity increase after oven dry of the mud samples. However, the thermal resistivity was not affected by the organic content of all the mud samples collected from the Ariake Sea. A small amount of thermal resistivity decrease after ignition loss for the samples collected from inside the sea. On the other hand, a small amount increase shows after the ignition loss for the samples collected from tidal flat mud (Fig 7).

Thermal diffusivity: Figure 8 shows the variation of thermal diffusivity with depth for all the Ariake mud. It is seen that in the tidal flats (sample 1 and sample 2); the thermal diffusivity is varied much in the different depths. On the other hand in the case of deep sea mud sample (sample 3, sample 4 and sample 5) the thermal diffusivity was constant in different depths. This is due to a small chance of turbulation in the deep sea bed floor. However, in the tidal flat area during the low tide, the tidal mud is exposed directly to the sunlight and during the ebb tide; a lot of foreign matters come and disturbs the homogeneity in the mud of the tidal mud layers. It is seen that in the deep sea mud, the 
value of thermal diffusivity is always in $0.12 \times 10^{-6}$ $\mathrm{m}^{2} / \mathrm{s}$. In the tidal flat, the peak reached at $0.13 \times 10^{-6}$ $\mathrm{m}^{2} / \mathrm{s}$ in different depths. Thermal diffusivity is decreased $10-30 \%$ after oven dry for the different samples (Fig. 9). To observe the effect of the organic matter content to the thermal diffusivity of the Ariake mud, ignition loss test was performed. It is seen that after ignition loss, thermal diffusivity increased $10-40 \%$ in different samples (Fig. 10).

Volumetric heat capacity: The volumetric heat capacity of the tidal mud refers to the value which indicates the ability to store heat. If the volumetric heat capacity of a soil is high then the soil is more stable in terms of temperature change or the thermal environment. Figure 11 illustrates the variation of volumetric heat capacity with depth of the various samples. Sample 2 shows a great variation in volumetric heat capacity. The peak shows at $0.15 \mathrm{~m}$ depth and value is about $6.4 \mathrm{MJ} / \mathrm{m}^{3}{ }^{\circ} \mathrm{C}$. Clay soil generally has higher volumetric heat capacity than sandy soil for the same water content and soil density ${ }^{[9]}$. Volumetric heat capacity is very important for the acid infected tidal mud. Sulphate reducing bacteria (SRB) plays an important role in the geo-environmental condition of the Ariake Sea. These Bacteria like the layer where the volumetric heat capacity is higher ${ }^{[14]}$. Because in that layer it shows the more stable condition which is liked by the bacteria. Figure 12 shows that volumetric heat capacity reduces about $80-90 \%$ after it was oven dried. Again, after ignition loss it increased about 30-50\% than before ignition loss. Organic content influence the thermal properties as well as the volumetric heat capacity of the soil. With increasing the organic content, the volumetric heat capacity decreases ${ }^{[7]}$. The temperature of underground soil is affected mainly by the soil thermal properties ${ }^{[17]}$ and these properties play a significant role in the geo-environmental condition in the global environment. The thermal properties of the mud are also induced by the mineralogical matter presence in the mud. The effects of this mineral matter on the thermal properties of the Ariake sea mud needs further study.

\section{CONCLUSIONS}

The thermal properties of the mud of the acid contaminated Ariake Sea was investigated through laboratory studies. The thermal properties of mud collected from tidal flat showed a different trend from the mud collected inside the sea due to the exposure to the sunlight and the tidal wave turbulation in the tidal flat areas. Thermal conductivity of the Ariake sea mud reduced up to $85-90 \%$ after it was oven dried and increased by 10-30 \% after the ignition loss test was carried out. Thermal resistivity of the Ariake mud increased dramatically after oven dried and it was less affected by the organic matter. Thermal diffusivity decreased 10-30 \% after oven dry however it was increased $10-40 \%$ after the ignition loss test. The volumetric heat capacity of the Ariake mud was reduced up to $80-90 \%$ and increased up to $30-40 \%$ by the water content and organic content, respectively.

\section{REFERENCES}

1. Anandkumar K., Venkatesan R. and Prabha T. 2001. Soil thermal properties at Kalpakkam in coastal south India. Earth Planet Science, 110 (3): 239-245

2. Azad K.A., Ohira S.I., Oda M. and Toda K. 2005. On-site measurements of hydrogen sulphide and sulfur dioxide emissions from tidal flat sediments of the Ariake Sea, Japan. Atmospheric Environment, 39: 6077-6087

3. Ben-Dor.E, and Banin A. 1989. Determination of organic matter content in arid-zone soils using a simple loss-on-ignition method.Commun. Soil Science Plant Analysis, 20:1675-1695

4. Blanchard G.F.,Guarini P. and Richard P. 1997. Seasonal effect on the relationship between the photosynthetic capacity of intertidal microphytobenthos and temperature. Journal of Phycology, 33:723-728

5. De Vries D A 1952. The thermal conductivity of soil. Meded. Landbouwhogesch, Wageningen

6. De Vries D A 1963. Thermal properties of soils. In: Physics of Plant Environment. Amsterdam, Holland.

7. Ekwue E., Stone R.,Maharaj V. and Bhagwat D. 2005. Thermal conductivity and diffusivity of four Trinidadian soils as affected by peat content. Transactions of the ASAE. 48(5): 1803-1815

Hamdeh H.N 2003. Thermal properties of soils as affected by density and water content. Biosystems Engineering, 86(1): 97-102

8. Hamdeh H.N and Reeder R C 2000. Soil thermal conductivity: effects of density, moisture, salt concentration, and organic matter. Soil Science Society of America Journal, 64: 1285-1290

9. Hayashi S. and Du Y.J. 2005. Effect of acid treatment agent of sea laver on geo-environmental properties of tidal flat muds in the Ariake Sea. Journal of ASTM International, Vol.3, No.4, pp. 431-439 
10. Holmer, M and P. Storkholm, 2001. Sulphate reduction and sulfur cycling in lake sediments: a review. Freshwater Biology, 46: 431-451

11. Hosokawa Y, Kiebe E.,Miyoshi Y.,Kuwae T. and Furukawa K. 1996. Distribution of aerial filtration rate of short-necked clam in coastal tidal flat. The technical note of the port and harbour research institute, 844: 21 (in Japanese with abstract in English)

12. Moqsud M.A., Hayashi S., Du Y.J., Suetsugu D., Ushihara Y., Tanaka S. and Okuzono K. 2006. Effects of acid treatment on geo-environmental conditions in the Ariake Sea, Japan. The 21st ICSW, March 26-29. Philadelphia, USA.pp.436-445

13. Moqsud M.A., Hayashi S., Du Y.J., Suetsugu D. 2006a. Evaluation of thermal properties of the mud of the Ariake Sea. International Symposium on Lowland Technology, September 14-16. Saga, Japan, pp.263-268

14. Moqsud M.A., Hayashi S., Du Y.J., Suetsugu D. 2007. Assessment of thermal properties of the mud of the Ariake Sea. Daffodil International Journal of Science and Technology, Vol 2. (1): 1-6

15. Naidu A. and Singh D. 2004. A generalized procedure for determining thermal resistivity of soils. International Journal of Thermal Sciences. 43: $43-51$
16. Nassar Y.,Elnoman A.,Abutaima A., Yousif S. and Salem A. 2006. Evaluation of the underground soil thermal storage properties in Libya. Renewable Energy, 31: 593-598

17. Ohtsubo M., Egashira K. and Kashima K. 1995. Depositional and post depositional geochemistry and its correlation with geotechnical properties of the marine clays in Ariake bay. Geotechnique, 45:509-523

18. Ochsner T E., Horton R.,Ren T 2001. A new perspective on soil thermal properties. Soil Science Society of America Journal, 65: 1641-1647

19. Wierenga P J., Nielsen D.R and Hagan R M 1969. Thermal properties of soil based upon field and laboratory measurements. Soil Science Society of America Journal, 33: 354-360

20. Yadav M R and Saxena G S. 1973. Effect of compaction and moisture content on specific heat and thermal capacity of soils. Journal of Indian Society of Soil Science, 21:129-132. 